\title{
Einwirkung von Ammoniak auf Merkurocarbonat und Merkurosulfat.
}

\author{
Von \\ Hatidas Saha und Kumud Nath Ghoudhury. ${ }^{1}$
}

Im Anschluß an unsere früheren Untersuchungen ${ }^{2}$ beschäftigten wir uns mit der Einwirkung von starkem Ammoniak auf Merkurocarbonat und Merkurosulfat, worüber hier berichtet werden soll. Wie früher, wurde das ammoniakalische Filtrat der beiden Verbindungen im Vakuum über starker Schwefelsäure verdampft, und man erhielt in allen Fällen einen weißen Rückstand, den man nach dem Waschen über Calciumchlorid trocknete. In beiden Fällen war der Rückstand amorph beim Carbonat, jedoch erwies er sich als weich und leicht, während der aus dem Sulfat erhaltene schwer war. Die Analysenergebnisse führen für das Carbonat zu der Formel $\left(\mathrm{NH}_{2} \mathrm{Hg}\right)_{2} \mathrm{CO}_{3} .3 \mathrm{HgO} .5 \mathrm{H}_{2} \mathrm{O}$ und für das Sulfat $\left(\mathrm{NH}_{2} \mathrm{Hg}_{3} \mathrm{SO}_{4}, 2 \mathrm{HgO} .2 \mathrm{H}_{2} \mathrm{O}\right.$.

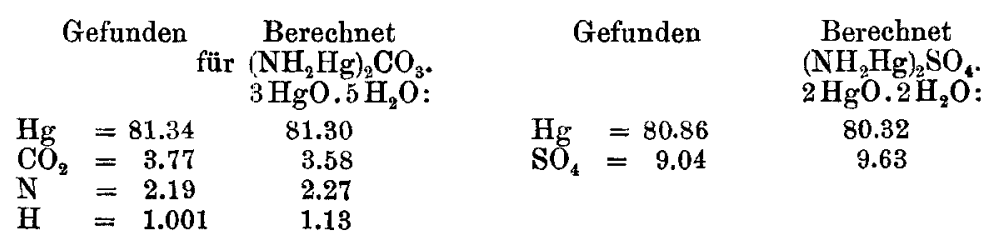

I. Merkurocarbonat wurde nach den Angaben von Roscoe aus Merkuronitrat und Kaliumbicarbonat hergestellt und auBerdem von E. Merck gezogen. Beide Proben gaben das gleiche Produkt mit Ammoniak. Beim Erhitzen lieferte der weiße Rückstand Ammoniak, Kohlendioxyd und Quecksilber, während ein schwarzer kohlehaltiger Rückstand verblieb. Das Quecksilber bestimmte man in üblicher Weise als Sulfid, den Stickstoff als Ammoniumchlorid, Wasserstoff durch Verbrennung und Kohlendioxyd nach dem Verfahren von Fresenius und Classhen.

\footnotetext{
1 Aus dem Manuskript ins Deutsche übertragen von I. Koppel-Berlin.

2 Z. anorg. Chem. 1910, 1911, 1912.
} 
240 H. Saha u. K. N. Choudhury. Einwirkung von Ammonial usw.

1. $0.2808 \mathrm{~g}$ Substanz gaben $0.265 \mathrm{~g} \mathrm{HgS}$.

2. $0.2808 \mathrm{~g} \quad, \quad, 0.0235 \mathrm{~g} \mathrm{NH}_{4} \mathrm{Cl}$.

3. $0.111 \mathrm{~g} \quad, \quad$ " $0.01 \mathrm{~g}$ Wasser.

4. $1.3024 \mathrm{~g} \quad, \quad, 0.0492 \mathrm{~g} \mathrm{CO}_{2}$.

II. Merkurosulfat wurde ron E. Merck bezogen. Man verdampfte das ammoniakalische Filtrat im Vakuum oder fällte es mit Wasser; aber die beiden so erhaltenen Stoffe waren nicht identisch; in letzterem Falle erlitt die Substanz in Berührung mit Wasser wahrscheinlich teilweise Hydrolyse. Die Ergebnisse der Analyse der ersten Probe sind folgende:

1. $0.856 \mathrm{~g}$ Substanz gaben $0.803 \mathrm{~g} \mathrm{HgS}$.

$2.1 .1014 \mathrm{~g} \quad " \quad, 0.2421 \mathrm{~g} \mathrm{BaSO}_{4}$.

Bengal, Indien, Chem. Laboratory, Dacea College.

Bei der Redaktion eingegangen am 17. Januar 1914. 